\title{
¿Miradas desde adentro? Dinámicas de representación de mujeres yalaltecas en la actualidad
}

Ariadna Itzel Solis Bautista

\section{Resumen}

En este artículo se exponen de manera breve las contradicciones, retos y potencias de las dinámicas de representación y autorrepresentación de mujeres indígenas, por medio de la fotografía. Se toma un retrato de la fotógrafa yalalteca Citlali Fabián para reflexionar entorno a la feminidad, la identidad, la comunidad y la etnicidad en México.

Palabras clave: representación, fotografía, mujeres indígenas, etnicidad.

\section{Views from Within? Dynamics of Representation of Yalaltecan WOMEN today}

\begin{abstract}
This article briefly exposes the contradictions, challenges and powers of the dynamics of representation and self-representation of indigenous women through photography. A portrait of the Yalaltecan photographer Citlali Fabián is taken as an example to reflect on femininity, identity, community and ethnicity in Mexico.
\end{abstract}

Keywords: representation, photography, indigenous women, ethnicity. 
"¿Miradas desde adentro? Dinámicas de representación de mujeres yalaltecas en la actualidad" Ariadna Itzel Solis Bautista

Vol. 22, Núm. 3, mayo-junio 2021 Revista Digital Universitaria

\section{Ariadna Itzel Solis Bautista}

\begin{abstract}
solis.ariadnx@gmail.com orcid.org/0000-0002-9488-4155

unam.academia.edu/AriadnaSolis
\end{abstract}

Instagram: @nietadelasnubes

Ariadna Solis es una mujer yalalteca migrante de segunda generación. Es politóloga e historiadora del arte por la Universidad Nacional Autónoma de México, actualmente es estudiante del Doctorado en Historia del Arte con la especialización en Arte Indígena en la Facultad de Filosofía y Letras de la unam. Es parte del colectivo Dill Yel Nbán, Grupo de transmisión y difusión de la lengua zapoteca. Ha publicado en revistas como Hysteria!, Extavío — revista electrónica de literatura comparada de la Universidad de Valencia - , en la Revista Kaypunku — de Estudios Interdisciplinarios de Arte y Cultura en el Perú - en la revista H-ART Revista de historia, teoría y crítica de arte de la Universidad de los Andes, y en la Pontificia Universidad Javeriana. Las líneas de investigación que trabaja están relacionadas con el estudio de la representación de mujeres indígenas en México, textiles, archivos, feminismos y luchas anticoloniales.

1 Yalálag es una comunidad zapoteca de la Sierra Norte de Oaxaca (Yalhalhj en zapoteco). Está ubicada en la Sierra Norte (también llamada Sierra Juárez), en el Distrito de Villa Alta, en el estado de Oaxaca, México, lugar del que provenimos Citlali y yo. Ambas somos migrantes de segunda generación.
"Primero me dio por pensar, indignada, que la identidad es como un vestido que tienes que ponerte, lo quieras o no lo quieras, te quede bien o no.

Después, sucumbí ante la presión y probé a ver si el hábito hacía al monje"

Maryse Condé, "Corazón que ríe, corazón que llora"

"Ben'n Yalhalhi" / "Soy de Yalálag" / "I'm from Yalálag" es el título de un proyecto documental de la fotógrafa yalalteca Citlali Fabián, compuesto en su mayor parte por fotografías realizadas en torno a las dinámicas comunitarias de Yalálag ${ }^{1}$, desde distintos territorios geográficos. En la actualidad, éste es uno de los proyectos documentales fotográficos más importantes elaborados dentro de la comunidad yalalteca, tanto por sus alcances dentro del campo del arte contemporáneo a nivel internacional, como por el alcance afectivo que ha tenido a nivel comunitario.

Las fotografías han sido realizadas desde hace casi diez años en diferentes locaciones geográficas donde se ha asentado la comunidad yalalteca. Principalmente, han sido tomadas en las fiestas que han tenido lugar en la comunidad serrana, en la ciudad de Oaxaca, en la Ciudad de México y en Los Ángeles, California. Su objetivo es retratar la transformación, los procesos migratorios y las adaptaciones que ha tenido la cultura yalalteca a través de las redes afectivas y familiares. 
“¿Miradas desde adentro? Dinámicas de representación de mujeres yalaltecas en la actualidad" Ariadna Itzel Solis Bautista

Vol. 22, Núm. 3, mayo-junio 2021

Revista Digital Universitaria

En este ensayo me dedicaré a exponer las tensiones que aparecen en la obra titulada "Melina", parte de los retratos de mujeres yalaltecas realizados por Citlali Fabián. En ellos es posible poner en marcha preguntas que tienen que ver con las estrategias de autorrepresentación de mujeres indígenas en sociedades complejas. Estrategias que tienen que ver con la presencia de nuestros cuerpos, su reconocimiento y la puesta en marcha de la comunidad.

Me enfocaré solo en este retrato porque en él encuentro claves para repensar nociones como la etnicidad, pertenencia e identidad, especialmente cuando estos problemas son encarnados en cuerpos feminizados y racializados. De esta manera, es posible problematizar las contradicciones que conlleva la construcción de una posible mirada "desde adentro".

\section{Ben'n Yalhalhj}

En esta serie, la principal preocupación es documentar las transformaciones de nuestra cultura tanto en la comunidad serrana como también la de la "diáspora". La serie se compone principalmente de retratos de miembros yalaltecas. Esta serie de fotografías ha sido presentada en distintas ocasiones, convocado por la misma comunidad yalalteca, en lugares como cafeterías, ferias culturales y fiestas. Pero principalmente, ha sido expuesta en Estados Unidos.

La fotografía que nos ocupa ha sido expuesta en muestras colectivas como "How We See Ourselves" en el festival Photoville que tuvo lugar en Brooklyn, Nueva York en septiembre de 2019, en charlas individuales como The National Geographic Storytellers Summit, que tuvo lugar en Washington, D.C., en enero de 2020 y también en una muestra colectiva titulada "The Fence" organizado por el festival Photoville y que tuvo lugar en Nueva York en Septiembre de 2020. Más recientemente está en marcha la "ocupación" de estas fotografías en el espacio público de la ciudad de Oaxaca, específicamente en el centro histórico, en colaboración con el estudio de arte y diseño Kadabra.

Citlali Fabián ha elegido la palabra documental para describir su propio proyecto y, en específico, la parte en la que se encuentra este retrato. El tema central es la transformación de nuestra cultura; sin embargo, los principales espacios en donde su trabajo circula están más ligados al ámbito del arte contemporáneo. Esto le permite recibir financiamiento para su proyecto de instituciones como National Geographic y al mismo tiempo posicionarlo en el extranjero con mayor facilidad. Así, en la propuesta de Citlali coexisten, por un lado, una preocupación artística y documental a manera de "registro", pero también, por el otro, de reconstrucción de historias y sobretodo de reconocimiento comunitario. Navegar entre estos dos formatos también funciona como un lugar para problematizar y cuestionar el lugar de "verdad" que suelen atravesar los proyectos documentales hechos especialmente sobre comunidades indígenas.

Dentro de esta serie de fotografías, podemos encontrar a muchas mujeres yalaltecas retratadas. En las imágenes suelen estar los temas de la tradición, el linaje 
materno, la familia, la transformación de la vestimenta y el sostenimiento de las fiestas a partir de los oficios de las mujeres; es decir, de manera recurrente, se pueden ver representadas a las mujeres yalaltecas como "guardianas de la cultura". Esto último es importante tenerlo en cuenta, especialmente cuando hablamos de representaciones que se dan en el espacio público, puesto que muchas veces se enfatiza ese lugar feminizado. Se trata de imágenes en donde acciones como echar tortillas, tejer o bailar quedan en el foco de la composición. Ejemplos de ello podemos verlos en la calle principal de la comunidad serrana de Yalálag, donde son las mujeres, una vez más, quienes aparecen como sujetos de salvaguarda de la cultura (ver imagen 1).
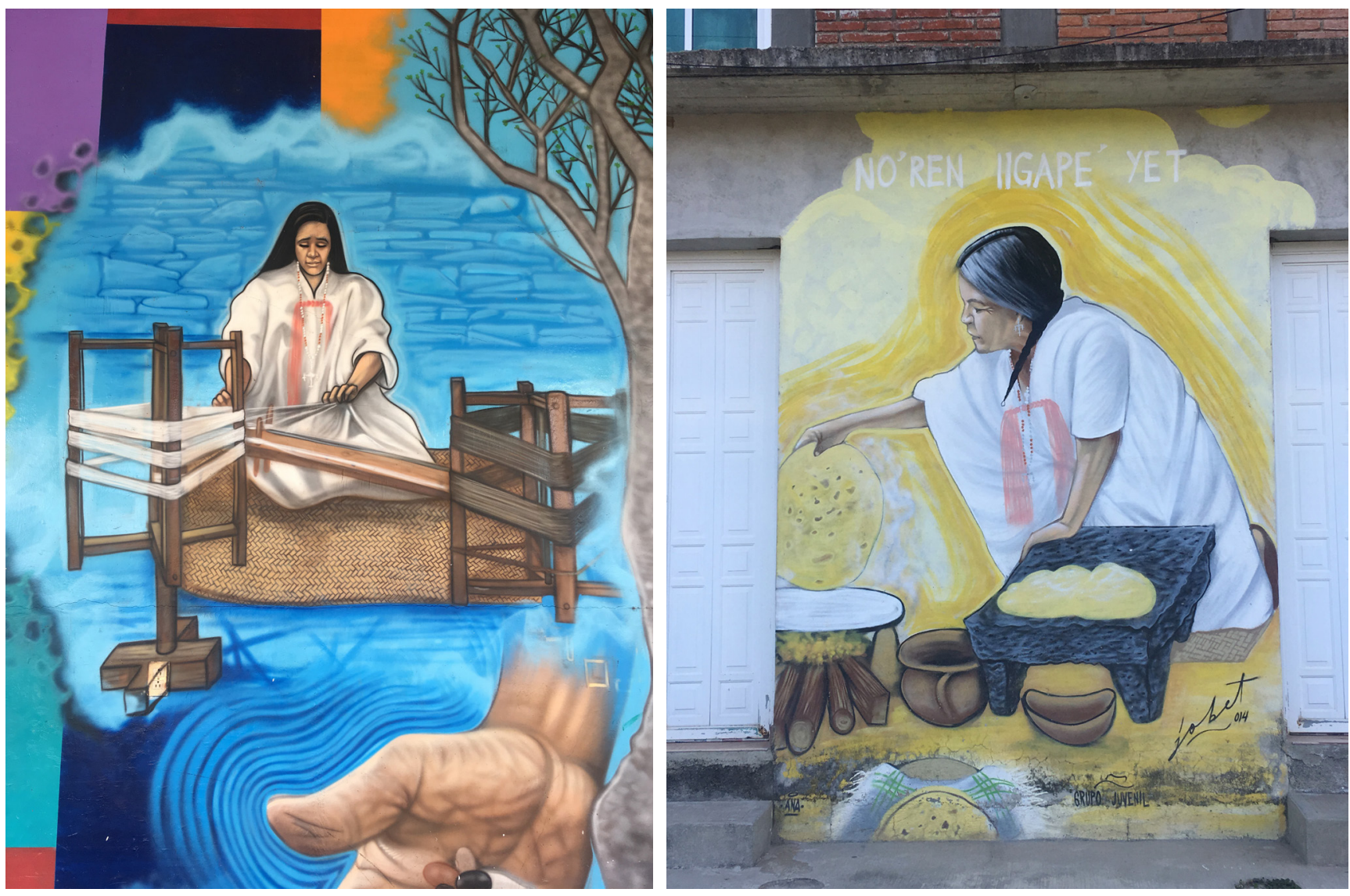

Ilustración 1. Murales en la calle principal de Yalálag. Fotografía de Ariadna Solis.

2 Forma de hacer fotografía etnográfica que resalta las características "culturales" y "fenotípicas" de los distintos pueblos originarios en México.

Para conecer más, se puede consultar "Fotografiar al indio.

Un breve estudio sobre la antropología y la fotografía mexicana" de Mariana da Costa Petroni.
Esta tradición de representación se alimenta mucho de los "tipos populares"2 generados en su mayoría en el siglo xx, y en donde un cúmulo de cánones estéticos se filtran en la manera en que miramos la identidad indígena feminizada y la naturalización de su lugar en la preservación de la cultura. Podríamos decir que la representación de las mujeres, a partir del uso de estas imágenes, ha servido para conservar y visibilizar "la identidad", las tradiciones y lo que se ha pensado que es "la esencia" de lo yalalteco, pero con intereses muy específicos, a veces lejanos a los de la misma comunidad, otras, no tanto.

Ahora, un tema importante en estas representaciones ha sido el uso del llamado "traje tradicional". Insisto en poner atención a las prendas que aparecen en los retratos de mujeres yalaltecas puesto que la ropa funciona también como 
un lugar de agencia, de enunciación y de pertenencia, que pone en tensión los conceptos de identidad, pertenencia y etnicidad³.

En este sentido, cabe preguntarse cómo estamos configurando estas imágenes "propias" o "desde adentro". Teniendo en cuenta que la mirada que enfoca nunca es objetiva o transparente para elegir sus temas, sus encuadres o sus sujetos, es necesario profundizar en los elementos y las formas que aparecen en las representaciones cuando el interés principal es el proceso mismo de representarse, de historizarse y de re-conocerse, gestos a los que hay que prestar atención.

\section{Melina}

Ilustración 2. Melina Monserrat, Oaxaca, junio de 2018. Fotografía de Citlali Fabián.

${ }^{3}$ Se entenderá como étnicas aquellas identidades que se insertan en el discurso de lo nacional multicultural. Es decir, lo étnico en su sentido menos crítico es aquello originario que sustenta, en su homogeneización, la conformación de una identidad nacional. En este sentido, se trata de un rescate selectivo del pasado, que favorece y reproduce la integración de los pueblos indígenas al proyecto de Estado-Nación y que presupone la vestimenta, la lengua y las costumbres como signos esenciales para la identidad indígena (Gutiérrez Chong, 2012). Rita Segato describe con mayor claridad este fenómeno como "Identidades Políticas Transnacionales" (2007)

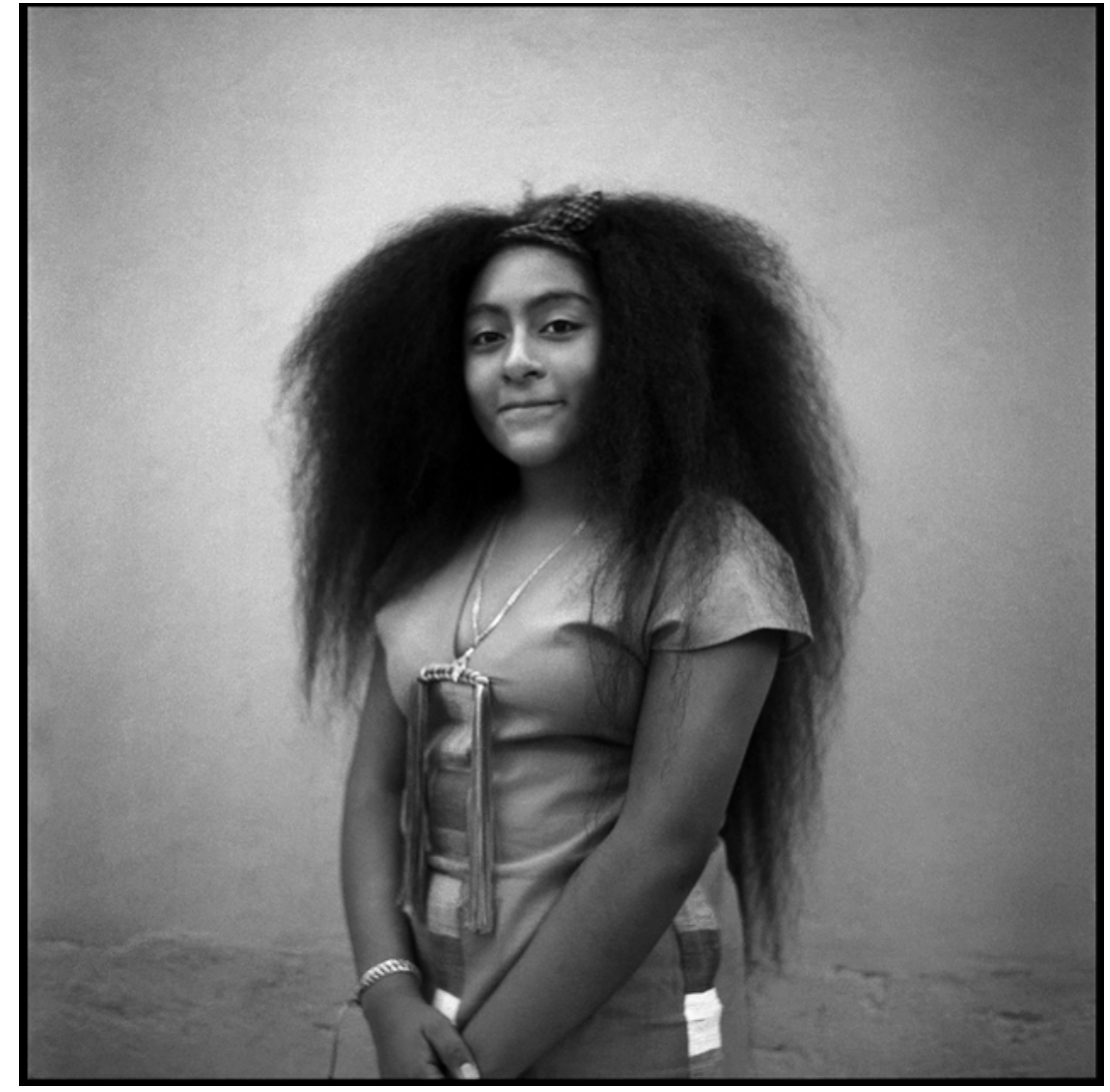

Esta fotografía me parece importante por varias cuestiones. Se trata de un plano medio en donde la figura central es Melina, una joven yalalteca, con un huipil o blusa-huipil "moderna". Se trata de una blusa corta, pegada al cuerpo, con un escote en $v$, que nos conduce a la característica trenza de los huipiles yalaltecos y al bordado propio de los huipiles "antiguos". Melina mira sonriente a la cámara y se agarra las manos al frente; se coloca en posición de tres cuartos, lo que permite ver de mejor manera su cabellera y su blusa. En la descripción de la foto, tomada de Instagram, se puede leer su nombre, la fecha y lugar en la que fue tomada, y una serie de hashtags o etiquetas que ayudan a encontrar la fotografía en esta red. Algunos ejemplos son "descendencia yalalteca", "belleza 
"¿Miradas desde adentro? Dinámicas de representación de mujeres yalaltecas en la actualidad" Ariadna Itzel Solis Bautista

Vol. 22, Núm. 3, mayo-junio 2021

Revista Digital Universitaria

oaxaqueña", entre otros, en los que incluyen descripciones de la técnica y el formato de la imagen. Esta foto de Melina es importante porque en retratos de mujeres yalaltecas es muy difícil encontrarse con fotografías de mujeres con ascendencia negra y que la enuncien con un particular énfasis. Aquí la clave para la lectura se encuentra en el arreglo específico que escogió Melina.

Citlali me platicó que conoció a Melina en la ciudad de Oaxaca, en la fiesta de San Juan, que es organizada en junio de todos los años en la colonia Yalálag, en la ciudad de Oaxaca. Se encontraron en esta celebración y Citlali le preguntó si podía fotografiarla. Melina había decidido asistir a la fiesta de San Juan arreglada de esta manera. Como pocas veces visto en mujeres yalaltecas, dejó su cabellera suelta y se arregló el frente con un listoncito de puntos. Esa forma particular de arreglar su cabello es un signo que permite que se desencadenen procesos de identificación colectiva, que quizás no serían tan inmediatos si el arreglo de Melina hubiese sido distinto.

La construcción misma de este retrato es interesante, puesto que tuvo lugar en el contexto de una fiesta comunitaria, en donde las mujeres eligen, a través de su vestimenta y su arreglo, signos para construir su identidad colectiva. Preguntarse por qué Citlali decide "neutralizar" su presencia con el fondo plano de una pared y no inscribirla en el ámbito de la celebración es importante, porque si bien se inserta en una tradición estilística del retrato, me parece que también desestabiliza y desnaturaliza la localización de Melina al ámbito de la fiesta o del paisaje, algo sumamente común al representar a sujetxs indígenas. Y, aunque pareciera un fondo clásico de una foto de estudio, la textura de la parte inferior de la fotografía nos deja saber que es una pared, muy probablemente en lo público, algo que se reforzará posteriormente.

La puesta en circulación de estas representaciones en plataformas accesibles para la comunidad es muy importante, ya que permite construir y problematizar a nuestras comunidades, que están inscritas en procesos de negociación de la identidad, o lo que Deleuze y Guattari (2012) entienden como rostrificación. Ésta es proceso en donde se conjuntan a la vez otros de subjetivación y de significancia dentro de un entramado social muy específico. Procesos que concentran imaginarios en un cuerpo específico, imaginarios que se replican pero que también se subvierten.

El retrato de Melina emplaza de manera particular los procesos de identidad de las mujeres indígenas, que suelen ser complejos en México. Ejemplo de ello es la frecuente invisibilización de nuestras raíces negras, ante la constante estigmatización y discriminación que se sufre por estas corporalidades. La fotografía de Melina también nos podría servir para repensar en los cánones de "bellezas indígenas", o como les llama Citlali "bellezas oaxaqueñas", que vemos circular en el imaginario social. En este sentido, en distintas fotografías, se ha intentado relacionar el cabello desarreglado con nociones de atraso; en contraste, se fomenta el vínculo del progreso con imágenes en donde el cabello de mujeres indígenas aparece especialmente arreglado. También se ha pasado por el uso de elaboradas trenzas o un cabello lacio prístino para enfatizar lo que se ha entendido 
como "bellezas indígenas". A diferencia de esas asociaciones, el cabello de Melina en esta fotografía aparece cuidadosamente acomodado, pero dejando ver que es crespo, signo de su ascendencia, que muestra con orgullo. El cabello de Melina en este retrato aparece como un signo de su negritud, de la lucha negra que cada vez encuentra más fuerza al desafiar el tabú de llevar el cabello afro "al natural".

Es necesario poner atención en los significados polivalentes de la ropa, así como los adornos del cuerpo y del cabello, pero también del mismo cuerpo que porta esos signos como una forma de negociación, donde se define un determinado cuerpo público consciente de la construcción de su identidad, que atraviesa procesos de etnicidad. Este retrato abre espacios de posibilidad de enunciación política a muchos niveles, especialmente cuando hablamos en términos de comunidades transgeográficas.

De manera reciente, con motivo del Día Internacional de la Lengua Materna, este retrato fue llevado al espacio público en la ciudad de Oaxaca; se encuentra en la calle 5 de mayo, una calle a unos pasos de Santo Domingo en el centro histórico. El formato de la fotografía fue modificado para dar paso a una imagen circular que, además de recortar el fondo, le da la apariencia de una "aureola", que se encuentra principalmente en imágenes religiosas. Se acompañó la fotografía con el texto bilingüe "Cha be'nha Ilislas Iliu 'situlhe bi bilhaka gapchi da bkuan xtaullo ka" - "Si el viento nos lleva lejos, mis hermanas cuidarán lo que nos heredaron nuestros ancestros" - .

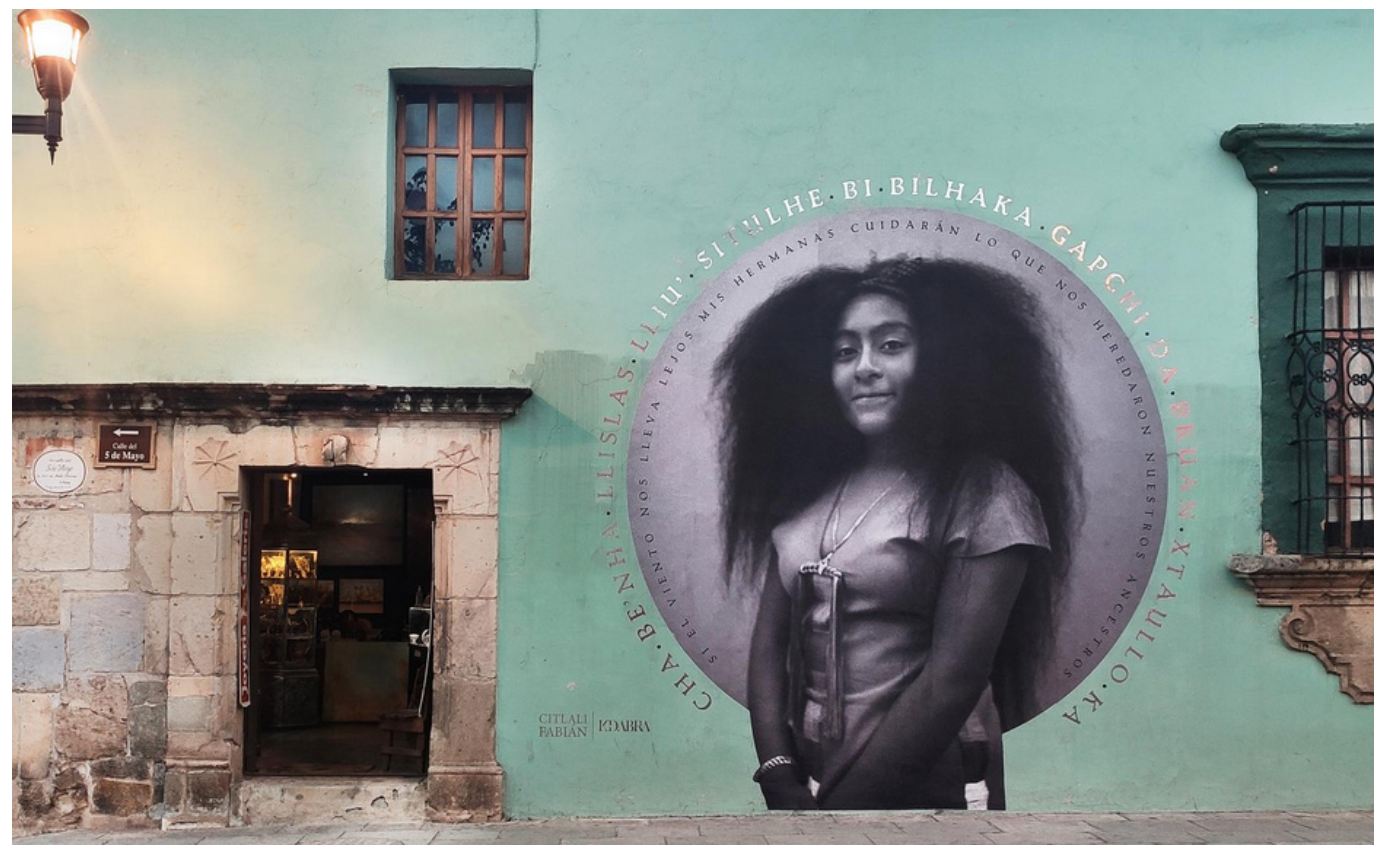

Si bien es clarísima la potencia de la ocupación de la imagen de Melina en el espacio público, queda pendiente la problematización de todos los elementos encontrados: el centro histórico tan pensado para el turismo internacional, la aureola recurrente en representaciones "virginales" y el texto mismo, en donde a pesar de que se visibiliza el papel de responsabilidad, cuidado, resistencia y sostenimiento que han 
"¿Miradas desde adentro? Dinámicas de representación de mujeres yalaltecas en la actualidad" Ariadna Itzel Solis Bautista

Vol. 22, Núm. 3, mayo-junio 2021

Revista Digital Universitaria

realizado históricamente las mujeres, a mi parecer, vuelve a caer en la trampa de naturalizar y responsabilizarlas de salvaguardar la cultura. En particular, "si el viento nos lleva lejos" es otra forma de enunciar la migración que nos atraviesa, no sin antes tomar el papel de responsabilidad que nos atañe en la participación y en la conformación de lo comunitario, como mujeres migrantes yalaltecas.

\section{Conclusiones}

Posar para la foto y tomar la fotografía puede entenderse como un acto performático en tanto que devela la presencia del cuerpo. Posar activa una serie de mecanismos que en el caso especifico de nuestra comunidad nos permite replantear genealogías, procesos de identificación y formas de representación estética, pero también política. Cuando posamos, cuando somos retratados desde un determinado lugar, somos partícipes de una conversación visual colectiva, y nos dejamos ser vistos de cierta forma, a través de determinados signos, de ciertas plataformas y gestos.

En ambas fotografías se juega a la representación de lo que significa ser una mujer indígena en México en estos días: para quién se está pensando esta representación y quién puede participar de esta conversación. Las fotografías de Citlali Fabián, lejos de jugarse entre la representación del folclore o lo pintoresco, logran reivindicar una presencia que sabe su agencia al momento de construir las representaciones, pero que también se sabe atrapada por la construcción de cánones universales que intentan capturar las identidades a lugares fijos, entendidos como étnicos.

Estos retratos aparecen como un campo semiótico en el que se juega la etnicidad, la feminidad, la pertenencia. La autorrepresentación en estos casos es importante, no porque nos dé un acceso directo a la verdad de los pueblos indígenas, sino porque se juega una forma de política. Se está jugando la autodeterminación, el reconocimiento y el posicionamiento político, tanto de las mujeres que aparecen en el retrato, como de Citlali que ha decidido fotografiarlas y de nosotras que observamos las fotografías.

La pregunta por la construcción de la otredad, aunque debe hacer énfasis en quién mira, debe preguntar obligatoriamente cómo se mira, en dónde se mira y cómo se toma responsabilidad en la conformación de la comunidad. Hablar de miradas desde adentro nos sirve porque nos permite distinguir intereses. No obstante, queda la cuestión de cómo hacer para subvertir la normalización visual de nuestras representaciones. Para ello, se puede empezar por reconocer la complicidad en cómo somos producidos como sujetos, especialmente cuando se está traduciendo de una cultura a otra, de contextos como la fiesta a la sala de museo, de las fotografías en Instagram al ámbito académico, de la fiesta al centro histórico de Oaxaca.

En todo caso, entender estas fotografías "desde adentro" debe guiarnos a entender que nuestro posicionamiento indígena no es la romantización de nuestras identidades, sino ante todo es la politización de nuestras experiencias. En estos contextos, ¿quién puede representar a quién? 


\section{Referencias}

* Da Costa A. Petroni, M. (2009, mayo-agosto). Fotografiar al indio. Un breve estudio sobre la antropología y la fotografía mexicana. Dimensión Antropológica, 46, 183215. https://www.dimensionantropologica.inah.gob.mx/?p=3874

Deleuze, G. y Gauttari, F. (2012). Mil mesetas: capitalismo y esquizofrenia. PRE-TEXTOS.

* Fabián, C. (2019, abril-junio). Mestiza de Yalálag. La palabra y el hombre. Revista de la Universidad Veracruzana, 48, 49-62. https://doi.org/10.25009//pyh.v0i48.2892

- Fabián, C. (2021, febrero). Cuando el viento nos Ileva lejos, taking over public space. http://www.citlalifabian.com/cuando-el-viento-nos-lleva-lej

* Gonzáles, D. (2019). A Mexican Photographer Explores the Enduring Bonds of Her Indigenous Culture. The New York Times. https://cutt.ly/XxWFOnQ

* Gutiérrez Chong, N. (2012). Mitos nacionalistas e identidades étnicas. Los intelectuales indigenas y el Estado mexicano. Instituto de Investigaciones Sociales, UnAm.

* Segato, R. (2007). La Nación y sus otros: Raza, etnicidad y diversidad religiosa en tiempos de políticas de la identidad. Prometeo Libros.

* Solis Bautista, A. I. (2019). La práctica textil y la noción de lo común. Tejer y vestir el huipil en Villa Hidalgo Yalálag, Oaxaca [Tesis de Maestría en Historia del Arte, Universidad Nacional Autónoma de México]. Tesiunam. https://ru.dgb.unam.mx/ handle/DGB_UNAM/TES01000790442.

\section{Cómo CITAR ESTE ARTículo}

* Solis Bautista, Ariadna Itzel.(2021, mayo-junio). ¿Miradas desde adentro? Dinámicas de representación de mujeresyalaltecas en la actualidad. Revista Digital Universitaria (RDU), 22(3). Dol: http://doi.org/10.22201/cuaieed.16076079e.2021.22.3.3 